Pacific Journal of Mathematics

AN INVARIANT SUBSPACE THEOREM OF J. FELDMAN 


\title{
AN INVARIANT SUBSPACE THEOREM OF J. FELDMAN
}

\author{
T. A. Gillespie
}

Theorem. Let $t$ be a quasi-nilpotent bounded linear operator on a complex normed space $X$ of dimension greater than one. Suppose further that there is a sequence $\left\{p_{n}(t)\right\}$ of polynomials in $t$ and a nonzero compact operator $s$ on $X$ such that $p_{n}(t) \rightarrow s$ (in norm) as $n \rightarrow \infty$. Then $t$ has a proper closed invariant subspace.

In [3], Feldman proves this theorem in the case when $X$ is a Hilbert space. By adapting the proof given by Bonsall [2, Theorem (20.1)] of the Bernstein-Robinson invariant subspace theorem [1], the result can be shown to hold when $X$ is a normed space, the necessary changes in the proof given in [2] being suggested by [3]. For the sake of completeness, the proof below repeats the relevant arguments in [2]. We need the following notation and simple results.

(i) If $E$ is a nonempty subset of $X$ and $x \in X$, the distance from $x$ to $E, d(x, E)$, is defined by

$$
d(x, E)=\inf \{\|x-y\|: y \in E\} .
$$

(ii) Given a sequence $\left\{E_{n}\right\}$ of linear subspaces of $X$, define $\lim \inf E_{n}=\left\{x \in X: \exists\right.$ a sequence $\left\{x_{n}\right\}$ with $x_{n} \in E_{n}$ and $\left.x_{n} \rightarrow x\right\}$. It is clear that $\lim \inf E_{n}$ is a closed linear subspace of $X$ and

$$
\lim \inf E_{n}=\left\{x \in X: d\left(x, E_{n}\right) \rightarrow 0 \quad \text { as } \quad n \rightarrow \infty\right\} .
$$

(iii) Given a finite dimensional subspace $E$ of $X$ and $x \in X, \exists u \in E$ such that $\|x-u\|=d(x, E)$. We call such a $u$ a nearest point of $E$ to $x$. Also, if $F$ is a finite dimensional subspace of $X$ such that $F \supset E, F \neq E, \exists v \in F$ such that $\|v\|=1=d(v, E)$.

Proof of theorem. Let $e \in X,\|e\|=1$. Clearly we may assume that $X$ has infinite dimension, and that $e, t e, t^{2} e, \cdots$ are linearly independent. Let $E_{n}$ be the linear span of $\left\{e, t e, \cdots, t^{n-1} e\right\}$, and choose $e_{n} \in E_{n}$ such that

$$
\left\|e_{n}\right\|=1=d\left(e_{n}, E_{n-1}\right) .
$$

Since $E_{n}$ is the linear span of $\left\{E_{n-1}, t^{n-1} e\right\}$, for each integer $n$ there is a unique $\alpha_{n} \in C, \alpha_{n} \neq 0$, such that

$$
e_{n}-\alpha_{n} t^{n-1} e \in E_{n-1} \text {. }
$$

Since $t E_{n-1} \subset E_{n}$, (1) gives 
(2)

$$
t^{r} e_{n}-\alpha_{n} t^{n+r-1} e \in E_{n+r-1}
$$

for $n \geqq 1, r \geqq 1$. Also, replacing $n$ by $n+r$ in (1),

$$
e_{n+r}-\alpha_{n+r} t^{n+r-1} e \in E_{n+r-1},
$$

and hence, by (2) and (3),

$$
t^{r} e_{n}-\frac{\alpha_{n}}{\alpha_{n+r}} e_{n+r} \in E_{n+r-1}
$$

for $n \geqq 1, r \geqq 1$. We note that, since $d\left(e_{n}, E_{n-1}\right)=1$, it follows from (4) that

$$
d\left(t^{r} e_{n}, E_{n+r-1}\right)=\frac{\left|\alpha_{n}\right|}{\left|\alpha_{n+r}\right|} \quad(n, r \geqq 1)
$$

We show that there is a subsequence $\left\{\alpha_{j(n)} / \alpha_{j(n)+1}\right\}$ of $\left\{\alpha_{n} / \alpha_{n+1}\right\}$ such that $\alpha_{j(n)} / \alpha_{j(n)+1} \rightarrow 0$ as $n \rightarrow \infty$. (This corresponds to the lemma in [3]). Suppose not. Then

$$
\liminf _{n \rightarrow \infty}\left|\frac{\alpha_{n}}{\alpha_{n+1}}\right|=\lambda>0
$$

and so there exists $n_{0}$ such that

$$
\left|\frac{\alpha_{n}}{\alpha_{n+1}}\right|>\lambda / 2 \quad \text { if } \quad n \geqq n_{0} .
$$

Since

$$
\begin{gathered}
\left\|t^{r}\right\| \geqq\left\|t^{r} e_{n}\right\| \geqq d\left(t^{r} e_{n}, E_{n+r-1}\right)=\left|\frac{\alpha_{n}}{\alpha_{n+r}}\right|, \\
\left\|t^{r}\right\| \geqq \prod_{j=n}^{n+r-1}\left|\frac{\alpha_{j}}{\alpha_{j+1}}\right| \cdot
\end{gathered}
$$

Taking $n=n_{\mathrm{c}}$, this gives

and so

$$
\left\|t^{r}\right\| \geqq(\lambda / 2)^{r} \quad(r \geqq 1),
$$

$$
\lim _{r \rightarrow \infty}\left\|t^{r}\right\|^{1 / r} \geqq \lambda / 2>0,
$$

contradicting the quasi-nilpotence of $t$. Therefore we can find a subsequence $\{j(n)\}$ such that

$$
\frac{\alpha_{j(n)}}{\alpha_{j(n)+1}} \rightarrow 0 \quad \text { as } \quad n \rightarrow \infty
$$

i.e. such that 


$$
d\left(t e_{j(n)}, E_{j(n)}\right) \rightarrow 0 \text { as } n \rightarrow \infty .
$$

Define linear mappings $t_{n}: E_{n} \rightarrow E_{n}(n \geqq 1)$ by

$$
t_{n}\left|E_{n-1}=t\right| E_{n-1}, \quad t_{n}\left(e_{n}\right)=u_{n},
$$

where $u_{n}$ is a nearest point of $E_{n}$ to $t e_{n}$. We show that

$$
\left\|t x-t_{n} x\right\| \leqq d\left(t e_{n}, E_{n}\right)\|x\| \quad\left(x \in E_{n}, n \geqq 1\right) .
$$

Let $x \in E_{n}$. Then $x=y+\lambda e_{n}$ for some $\lambda \in C, y \in E_{n-1}$.

$$
\left\|t x-t_{n} x\right\|=\left\|\lambda t e_{n}-\lambda u_{n}\right\|=|\lambda| d\left(t e_{n}, E_{n}\right),
$$

and also

$$
\|x\| \geqq d\left(x, E_{n-1}\right)=d\left(\lambda e_{n}, E_{n-1}\right)=|\lambda| d\left(e_{n}, E_{n-1}\right)=|\lambda| .
$$

Therefore

$$
\left\|t x-t_{n} x\right\| \leqq d\left(t e_{n}, E_{n}\right)\|x\| \quad\left(x \in E_{n}, n \geqq 1\right) .
$$

From (5) and (6) we see that, if $\left\{x_{n}\right\}$ is a bounded sequence with $x_{n} \in E_{j(n)}$, then

$$
\left\|t x_{n}-t_{j(n)} x_{n}\right\| \rightarrow 0 \text { as } n \rightarrow \infty .
$$

From (7) it follows that if $\left\{H_{n_{k}}\right\}$ is a sequence of subspaces with $H_{n_{k}} \subset E_{j\left(n_{k}\right)}$ and $H_{n_{k}}$ invariant for $t_{j\left(n_{k}\right)}$, then lim inf $H_{n_{k}}$ is invariant for $t$.

We prove next, by induction on $k$, that for each integer $k$ there is a constant $A_{k}$ such that

$$
\left\|t^{k} x-t_{n}^{k} x\right\| \leqq A_{k} d\left(t e_{n}, E_{n}\right)\|x\| \quad\left(x \in E_{n}, n \geqq 1\right) .
$$

The case when $k=1$ is given by $(6),\left(A_{1}=1\right)$. Suppose that (8) holds for some $k$. Then, for $x \in E_{n}$,

$$
\begin{aligned}
\left\|t_{n}^{k} x\right\| & \leqq\left\|t^{k} x\right\|+A_{k} d\left(t e_{n}, E_{n}\right)\|x\| \\
& \leqq\left(\left\|t^{k}\right\|+A_{k} d\left(t e_{n}, E_{n}\right)\right)\|x\| \\
& \leqq\left(\left\|t^{k}\right\|+A_{k}\|t\|\right)\|x\| \\
& =B_{k}\|x\|, \quad \text { say . }
\end{aligned}
$$

Since $t_{n}^{k} E_{n} \subset E_{n}$, (6) gives

$$
\begin{aligned}
\left\|t t_{n}^{k} x-t_{n}^{k+1} x\right\| & \leqq d\left(t e_{n}, E_{n}\right)\left\|t_{n}^{k} x\right\| \\
& \leqq B_{k} d\left(t e_{n}, E_{n}\right)\|x\| .
\end{aligned}
$$

Therefore

$$
\begin{aligned}
\left\|t^{k+1} x-t_{n}^{k+1} x\right\| & \leqq\left\|t^{k+1} x-t t_{n}^{k} x\right\|+\left\|t t_{n}^{k} x-t_{n}^{k+1} x\right\| \\
& \leqq\|t\|\left\|t^{k} x-t_{n}^{k} x\right\|+\left\|t t_{n}^{k} x-t_{n}^{k+1} x\right\| \\
& \leqq\left(\|t\| A_{k}+B_{k}\right) d\left(t e_{n}, E_{n}\right)\|x\| .
\end{aligned}
$$


Hence, by induction, (8) is proved.

It follows immediately from (8) that, given a polynomial $p(t)$ in $t$, there is a constant $M$ such that

$$
\left\|p(t) x-p\left(t_{n}\right) x\right\| \leqq M d\left(t e_{n}, E_{n}\right)\|x\| \quad\left(x \in E_{n}, n \geqq 1\right) .
$$

Hence we can find positive constants $\left\{M_{r}\right\}_{r \geq 1}$ such that

$$
\left\|p_{r}(t) x-p_{r}\left(t_{n}\right) x\right\| \leqq M_{r} d\left(t e_{n}, E_{n}\right)\|x\|
$$

for $x \in E_{n}, n \geqq 1, r \geqq 1$.

Since $s t=t s$ and $s \neq 0$, we may assume that $s^{-1}(0)=(0)$, for otherwise $s^{-1}(0)$ is a proper closed invariant subspace for $t$. Therefore $s e \neq 0$, and we can choose $\alpha$ with $0<\alpha<1$ and $\alpha\|s\|<\|s e\|$. Choose sequences $\left\{E_{n}^{i}\right\}_{i=0}^{j(n)}$ of subspaces of $E_{j(n)}$ such that

$$
(0)=E_{n}^{0} \subset E_{n}^{1} \subset \cdots \subset E_{n}^{\jmath(n)}=E_{j(n)},
$$

where $\operatorname{dim} E_{n}^{i}=i$ and $E_{n}^{i}$ is invariant for $t_{j(n)}$. Since $d\left(e, E_{n}^{0}\right)=\|e\|=1$ and $d\left(e, E_{n}^{j(n)}\right)=0$, for each $n$ there is a greatest $i, i_{n}$ say, such that $d\left(e, E_{n}^{i_{n}}\right)>\alpha$. Put $F_{n}=E_{n}^{i_{n}}, G_{n}=E_{n}^{i_{n}+1}$. Then

$$
d\left(e, F_{n}\right)>\alpha, \quad d\left(e, G_{n}\right) \leqq \alpha \quad(n \geqq 1),
$$

and so

$$
e \notin \lim \inf F_{n_{k}}
$$

for any subsequence $\left\{n_{k}\right\}$. Let $y_{n}, z_{n}$ be nearest points of $G_{n}$ to $e$, se respectively, and let $v_{n} \in G_{n}$ with $\left\|v_{n}\right\|=1=d\left(v_{n}, F_{n}\right)$. We can write

$$
\begin{aligned}
& y_{n}=x_{n}+\beta_{n} v_{n} \\
& z_{n}=x_{n}^{\prime}+\beta_{n}^{\prime} v_{n},
\end{aligned}
$$

where $x_{n}, x_{n}^{\prime} \in F_{n}$ and $\beta_{n}, \beta_{n}^{\prime} \in C$. We have

$$
\begin{aligned}
\left|\beta_{n}\right| & =d\left(\beta_{n} v_{n}, F_{n}\right)=d\left(y_{n}, F_{n}\right) \leqq\left\|y_{n}\right\| \\
& \leqq\left\|y_{n}-e\right\|+\|e\|=d\left(e, G_{n}\right)+\|e\| \leqq 2\|e\| .
\end{aligned}
$$

Similarly

$$
\left|\beta_{n}^{\prime}\right| \leqq 2\|s e\|
$$

Also, for $n \geqq 1$,

$$
\begin{aligned}
\left\|s y_{n}\right\| & \geqq\|s e\|-\left\|s y_{n}-s e\right\| \geqq\|s e\|-\|s\|\left\|y_{n}-e\right\| \\
& =\|s e\|-\|s\| d\left(e, G_{n}\right) \geqq\|s e\|-\alpha\|s\|>0 .
\end{aligned}
$$

By the compactness of $s$ and the boundedness of $\left\{|| y_{n} \|\right\},\left\{\left|\beta_{n}\right|\right\},\left\{\left|\beta_{n}^{\prime}\right|\right\}$, we can find a subsequence $\left\{n_{k}\right\}$ such that

$$
\beta_{n_{k}} \rightarrow \beta, \quad \beta_{n_{k}}^{\prime} \rightarrow \beta^{\prime}, \quad s y_{n_{k}} \rightarrow y \quad \text { as } k \rightarrow \infty .
$$


We show that $y \in \lim \inf G_{n_{k}}$. Let $\varepsilon>0 . \quad \exists n_{0}$ such that

$$
\left\|s-p_{n_{0}}(t)\right\|<\frac{\varepsilon}{4\|e\|} .
$$

By (5), $\exists k_{0}$ such that

$$
d\left(t e_{j\left(n_{k}\right)}, E_{j\left(n_{k}\right)}\right)<\frac{\varepsilon}{4 M_{n_{0}}\|e\|} \quad \text { if } \quad k \geqq k_{0} .
$$

Since $\left\|y_{n}\right\| \leqq 2\|e\|(n \geqq 1)$, by $(9)$

$$
\left\|p_{n_{0}}(t) y_{n_{k}}-p_{n_{0}}\left(t_{j\left(n_{k}\right)}\right) y_{n_{k}}\right\| \leqq M_{n_{0}} d\left(t e_{j\left(n_{k}\right)}, E_{j\left(n_{k}\right)}\right) \cdot 2\|e\|
$$

for $k \geqq 1$. Therefore $k \geqq k_{0}$ implies that

$$
\begin{aligned}
\left\|s y_{n_{k}}-p_{n_{0}}\left(t_{j\left(n_{k}\right)}\right) y_{n_{k}}\right\| & \leqq\left\|s y_{n_{k}}-p_{n_{0}}(t) y_{n_{k}}\right\| \\
& +\left\|p_{n_{0}}(t) y_{n_{k}}-p_{n_{0}}\left(t_{j\left(n_{k}\right)}\right) y_{n_{k}}\right\| \\
& \leqq\left\|s-p_{n_{0}}(t)\right\|\left\|y_{n_{k}}\right\| \\
& +2 M_{n_{0}}\|e\| d\left(t e_{j\left(n_{k}\right)}, E_{j\left(n_{k}\right)}\right) \\
& \leqq \frac{\varepsilon}{4\|e\|} \cdot 2\|e\|+2 M_{n_{0}}\|e\| \cdot \frac{\varepsilon}{4 M_{n_{0}}\|e\|}=\varepsilon .
\end{aligned}
$$

Since $s y_{n_{k}} \rightarrow y, \exists k_{1} \geqq k_{0}$ such that $\left\|s y_{n_{k}}-y\right\|<\varepsilon$ if $k \geqq k_{1}$. Thus if $k \geqq k_{1}$,

$$
\begin{aligned}
\left\|y-p_{n_{0}}\left(t_{j\left(n_{k}\right)}\right) y_{n_{k}}\right\| & \leqq\left\|y-s y_{n_{k}}\right\|+\left\|s y_{n_{k}}-p_{n_{0}}\left(t_{j\left(n_{k}\right)}\right) y_{n_{k}}\right\| \\
& <\varepsilon+\varepsilon=2 \varepsilon .
\end{aligned}
$$

But $p_{n_{0}}\left(t_{j\left(n_{k}\right)}\right) y_{n_{k}} \in G_{n_{k}}$ since $G_{n_{k}}$ is invariant for $t_{j\left(n_{k}\right)}$, and so

$$
d\left(y, G_{n_{k}}\right) \leqq\left\|y-p_{n_{0}}\left(t_{j\left(n_{k}\right)}\right) y_{n_{k}}\right\|<2 \varepsilon \text { if } k \geqq k_{1} .
$$

Therefore $d\left(y, G_{n_{k}}\right) \rightarrow 0$ as $k \rightarrow \infty$, and $y \in \lim \inf G_{n_{k}}$.

Now by (11) $y \neq 0$, and so $\lim \inf G_{n_{k}}$ will be a proper closed invariant subspace for $t$ unless $\lim \inf G_{n_{k}}=X$. Thus we may suppose that $\lim \inf G_{n_{k}}=X$, and hence that $e, s e \in \liminf G_{n_{k}}$, i.e.

$$
d\left(e, G_{n_{k}}\right)=\left\|e-y_{n_{k}}\right\| \rightarrow 0 \text { as } k \rightarrow \infty
$$

and

$$
d\left(s e, G_{n_{k}}\right)=\left\|s e-z_{n_{k}}\right\| \rightarrow 0 \quad \text { as } \quad k \rightarrow \infty .
$$

Therefore

$$
x_{n_{k}}+\beta_{n_{k}} v_{n_{k}} \rightarrow e \text { and } x_{n_{k}}^{\prime}+\beta_{n_{k}}^{\prime} v_{n_{k}} \rightarrow s e \text { as } k \rightarrow \infty .
$$

Hence

$$
\beta_{n_{k}}^{\prime} x_{n_{k}}-\beta_{n_{k}} x_{n_{k}}^{\prime} \rightarrow \beta^{\prime} e-\beta s e \text { as } k \rightarrow \infty,
$$


and so

$$
\beta^{\prime} e-\beta s e \in \lim \inf F_{n_{k}} \text {. }
$$

If $\beta=0$ then $x_{n_{k}} \rightarrow e$ and $e \in \lim$ inf $F_{n_{k}}$, contradicting (10). So $\beta \neq 0$. If $\beta^{\prime} e-\beta s e=0$ then $\left(\beta^{\prime} \mid \beta\right) e=s e \neq 0$ and so $\beta^{\prime} \neq 0$. Then $s \neq\left(\beta^{\prime} \mid \beta\right) \mathscr{J}$ since $s$ is compact and $X$ has infinite dimension $(\mathscr{J}$ being the identity operator on $X$ ). Therefore

$$
0 \neq e \in\left(s-\frac{\beta^{\prime}}{\beta} \mathscr{J}\right)^{-1}(0)
$$

and $\left\{s-\left(\beta^{\prime} \mid \beta\right) \mathscr{F}\right\}^{-1}(0)$ is a proper closed invariant subspace for $t$. Finally, if $\beta^{\prime} e-\beta s e \neq 0$ then $\lim \inf F_{n_{k}} \neq(0)$, and so, by (10), $\lim \inf F_{n_{k}}$ is a proper closed invariant subspace for $t$.

\section{REFERENCES}

1. A. R. Bernstein and A. Robinson, Solution of an invariant subspace problem of K. T. Smith and P. R. Halmos, Pacific J. Math. 16 (1966), 421-431.

2. F. F. Bonsall, Compact Linear Operators, Lecture Notes, Yale University.

3. J. Feldman, Invariant subspaces for certain quasi-nilpotent operators (privately circulated).

Received August 18, 1967. This work was done at Yale University; the author was supported by a NATO Research Studentship.

EDINBURGH UNIVERSITY

SCOTLAND 


\section{PACIFIC JOURNAL OF MATHEMATICS}

\section{EDITORS}

\author{
H. ROYDEN \\ Stanford University \\ Stanford, California \\ R. R. Phelps \\ University of Washington \\ Seattle, Washington 98105
}

J. DUGUNDJI

Department of Mathematics

University of Southern California

Los Angeles, California 90007

RICHARD ARENS

University of California

Los Angeles, California 90024

\section{ASSOCIATE EDITORS}
E. F. BECKENBACH
B. H. NeumanN
F. WOLF
K. YosidA

\section{SUPPORTING INSTITUTIONS}

UNIVERSITY OF BRITISH COLUMBIA

CALIFORNIA INSTITUTE OF TECHNOLOGY

UNIVERSITY OF CALIFORNIA

MONTANA STATE UNIVERSITY

UNIVERSITY OF NEVADA

NEW MEXICO STATE UNIVERSITY

OREGON STATE UNIVERSITY

UNIVERSITY OF OREGON

OSAKA UNIVERSITY

UNIVERSITY OF SOUTHERN CALIFORNIA
STANFORD UNIVERSITY

UNIVERSITY OF TOKYO

UNIVERSITY OF UTAH

WASHINGTON STATE UNIVERSITY

UNIVERSITY OF WASHINGTON

AMERICAN MATHEMATICAL SOCIETY CHEVRON RESEARCH CORPORATION TRW SYSTEMS

NAVAL WEAPONS CENTER

Printed in Japan by International Academic Printing Co., Ltd., Tokyo, Japan 


\section{Pacific Journal of Mathematics}

\section{Vol. 26, No. $1 \quad$ November, 1968}

Efraim Pacillas Armendariz, Closure properties in radical theory......... 1

Friedrich-Wilhelm Bauer, Postnikov-decompositions of functors .......... 9

Thomas $\mathrm{Ru}-$ Wen Chow, The equivalence of group invariant positive definite

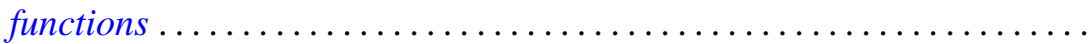

Thomas Allan Cootz, A maximum principle and geometric properties of

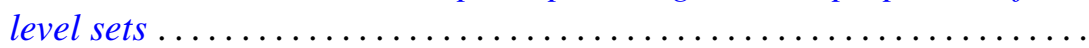

Rodolfo DeSapio, Almost diffeomorphisms of manifolds ............ 47

R. L. Duncan, Some continuity properties of the Schnirelmann density......

Ralph Jasper Faudree, Jr., Automorphism groups of finite subgroups of

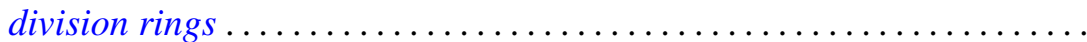

Thomas Alastair Gillespie, An invariant subspace theorem of $J$.

Feldman.........................................

George Isaac Glauberman and John Griggs Thompson, Weakly closed direct factors of Sylow subgroups .............................

Hiroshi Haruki, On inequalities generalizing a Pythagorean functional equation and Jensen's functional equation .....................

David Wilson Henderson, D-dimension. I. A new transfinite dimension.....

David Wilson Henderson, D-dimension. II. Separable spaces and

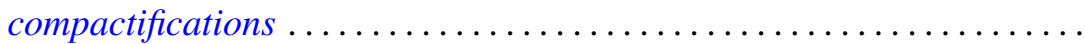

Julien O. Hennefeld, A note on the Arens products ............... 115

Richard Vincent Kadison, Strong continuity of operator functions ...

J. G. Kalbfleisch and Ralph Gordon Stanton, Maximal and minimal coverings of $(k-1)$-tuples by $k$-tuples.

Franklin Lowenthal, On generating subgroups of the Moebius group by pairs of infinitesimal transformations...

Michael Barry Marcus, Gaussian processes with stationary increments possessing discontinuous sample paths . .

Zalman Rubinstein, On a problem of Ilyeff ...

Bernard Russo, Unimodular contractions in Hilbert space. ...

David Lee Skoug, Generalized Ilstow and Feynman integrals...

William Charles Waterhouse, Dual groups of vector spaces . 